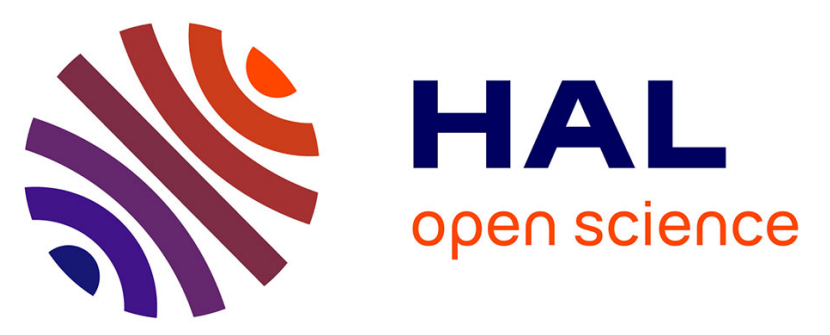

\title{
Vaccination and Risk for Developing Inflammatory Bowel Disease: A Meta-Analysis of Case Control and Cohort Studies
}

Guillaume Pineton De Chambrun, Luc Dauchet, Corinne Gower-Rousseau, Antoine Cortot, Jean-Frédéric Colombel, Laurent Peyrin-Biroulet

\section{To cite this version:}

Guillaume Pineton De Chambrun, Luc Dauchet, Corinne Gower-Rousseau, Antoine Cortot, JeanFrédéric Colombel, et al.. Vaccination and Risk for Developing Inflammatory Bowel Disease: A Meta-Analysis of Case Control and Cohort Studies. Clinical Gastroenterology and Hepatology, 2015, 13 (8), pp.1405-1415.e1. 10.1016/j.cgh.2015.04.179 . hal-01997123

\section{HAL Id: hal-01997123 https://hal.science/hal-01997123}

Submitted on 30 Jan 2019

HAL is a multi-disciplinary open access archive for the deposit and dissemination of scientific research documents, whether they are published or not. The documents may come from teaching and research institutions in France or abroad, or from public or private research centers.
L'archive ouverte pluridisciplinaire HAL, est destinée au dépôt et à la diffusion de documents scientifiques de niveau recherche, publiés ou non, émanant des établissements d'enseignement et de recherche français ou étrangers, des laboratoires publics ou privés. 


\title{
Vaccination and Risk for Developing Inflammatory Bowel Disease: A Meta-Analysis of Case-Control and Cohort Studies
}

\author{
Guillaume Pineton de Chambrun, ${ }^{*, \neq, \S, k}$ Luc Dauchet, ${ }^{\S, \pi}$ Corinne Gower-Rousseau, ${ }^{*, \neq, \S}$ \\ Antoine Cortot, ${ }^{*, \neq}, \S$ Jean-Frédéric Colombel, ${ }^{\#}$ and Laurent Peyrin-Biroulet ${ }^{\S, * *}$
}

*Gastroenterology and Hepatology Department, Lille University Hospital, Lille, France, "Epidemiological Department, Lille University Hospital, Lille, France; ${ }^{\ddagger}$ Lille Inflammation Research International Center LIRIC-UMR 995 Inserm, Université Lille 2, CHRU de Lille, Equipe IBD and Environmental Factors: Epidemiology and Functional Analyses, Lille University, Lille, France; $\S$ Public Health, Epidemiology and Economic Health, Registre Epimad, Maison Régionale de la Recherche Clinique, Centre Hospitalier Universitaire Régional, Lille Cedex, France; ${ }^{k}$ Gastroenterology and Hepatology Department, Montpellier University Hospital, Montpellier, France; "Department of Gastroenterology, Icahn Medical School of Medicine at Mount Sinai, New York, New York; **Inserm U954 and Department of Gastroenterology, Université de Lorraine, Nancy les Vandoeuvre, France

This article has an accompanying continuing medical education activity on page e130. Learning Objective-Upon completion of this activity, successful learners will be able to discuss the implication of vaccination and environmental factors in the development of inflammatory bowel disease.

BACKGROUND \& AIMS: Environmental factors may play a key role in the pathogenesis of inflammatory bowel disease (IBD). Whether vaccination is associated causally with IBD is controversial. We performed a meta-analysis of case-control and cohort studies on the association between vaccination and the risk for IBD.

METHODS:

Studies and abstracts investigating the relationship between vaccination and subsequent risk for developing IBD were reviewed. Childhood or adult immunizations with any vaccine type, at any dose, and with any vaccine schedule were used as inclusion criteria.

RESULTS:

Eleven studies were included in the systematic review and meta-analysis: 8 case-control studies and 3 cohort studies. Studied vaccines were bacille Calmette-Guérin), vaccines against diphtheria, tetanus, smallpox, poliomyelitis, pertussis, $\mathrm{H} 1 \mathrm{~N} 1$, measles, rubella, mumps, and the combined measles, mumps, and rubella vaccine. Only a few details about vaccine type or route of administration were found in studies. Overall, there was no association between childhood immunization and risk for developing IBD: bacille Calmette-Guérin, relative risk (RR) of 1.04 (95\% confidence interval [CI], 0.78-1.38), diphtheria, RR of 1.24 (95\% CI, 0.80-1.94), tetanus, RR of 1.27 (95\% CI, 0.77-2.08), smallpox, RR of 1.08 (95\% CI, 0.70-1.67), poliomyelitis, RR of 1.79 (95\% CI, 0.88-3.66), an measles containing vaccines, RR of 1.33 (95\% CI, 0.31-5.80) in cohort studies, and RR of 0.85 (95\% CI, 0.60-1.20) in case-control studies. Subgroup analysis for Crohn's disease (CD) and ulcerative colitis (UC) found an association between the poliomyelitis vaccine and risk for developing CD (RR, 2.28; 95\% CI, 1.12-4.63) or UC (RR, 3.48; 95\% CI, 1.2-9.71). The RR of developing IBD after H1N1 vaccination was 1.13 (95\% CI, 0.97-1.32).

CONCLUSIONS:

Results of this meta-analysis show no evidence supporting an association between childhood immunization or $\mathrm{H} 1 \mathrm{~N} 1$ vaccination in adults and risk of developing IBD. The association between the poliomyelitis vaccine and the risk for $\mathrm{CD}$ or UC should be analyzed with caution because of study heterogeneity.

Keywords: Crohn's Disease; Ulcerative Colitis; Poliomyelitis; BCG; Vaccine; Childhood.

The etiology of inflammatory bowel diseases (IBDs) including Crohn's disease (CD) and ul- cerative colitis (UC) remains unknown. The pathogen- esis of IBD is thought to involve an altered immune response against gut microflora in genetically predis- posed individuals, leading to mucosal inflammation and ulcerations. ${ }^{1,2}$ Currently, more than 100 suscepti- bility genes for $\mathrm{CD}$ and $\mathrm{UC}$ have been identified by a
Abbreviations used in this paper: BCG, bacille Calmette-Guérin; CD, Crohn's disease; $\mathrm{Cl}$, confidence interval; IBD, inflammatory bowel disease; IPV, injected inactivated vaccine; MMR, measles, mumps, rubella; $\mathrm{OR}$, odds ratio; OPV, oral live vaccine; RR, relative risk; UC, ulcerative colitis. 
genome-wide association scan study. ${ }^{3}$ Although genetic influence may play an important role in the development of IBD, several observations plead for equal implication of environmental exposure. ${ }^{4-6}$ The lack of complete penetrance of UC and CD among monozygotic twins and the limited familial occurrence of IBD (5\%$10 \%$ ) indicates that environmental factors play a role in the development of these disorders. ${ }^{7,8}$ Many environmental factors have been proposed as etiologic factors of $\mathrm{CD}$ or $\mathrm{UC}^{8-10}$

There is accumulating evidence that events early in life may have long-term effects on health and disease. ${ }^{8,11}$ In the same way, it has been suggested that attenuated live measles virus vaccine might lead to IBD. ${ }^{12}$ The first report on the risk of developing IBD after a measles vaccination in leads to international controversy and suspicion about vaccination safety. Since then, several population-based, case-control and cohort studies have investigated the potential link between childhood immunization and IBD with conflicting results. ${ }^{11-21}$ Different types of vaccines were studied such as poliomyelitis, measles, rubella, mumps, smallpox, pertussis, tetanus, diphtheria, and bacille Calmette-Guérin (BCG).

An attractive theory is that vaccination, which leads to a decrease in the prevalence of early childhood infections, may favor immunologic diseases. ${ }^{22}$ A direct effect of viral or bacterial components included in vaccines on the immune system also may be implicated. ${ }^{23}$ Finally, adjuvant contained in many vaccines, such as aluminum, could be at risk of overstimulating the immune system, leading to dysregulated inflammatory response. ${ }^{10,24}$ Overall, whether vaccination is associated causally with IBD remains controversial.

The aim of this study therefore was to perform a systematic review and meta-analysis of case-control and cohort studies on the association between vaccination and the risk of developing IBD.

\section{Methods}

\section{Search Strategy and Study Selection}

A systematic review and meta-analysis was conducted in accordance with guidelines for systematic reviews and meta-analyses published previously. ${ }^{25} \mathrm{~A}$ computerized search of the medical English and non-English literature was conducted using MEDLINE (1970 to June 2014), EMBASE, and the Cochrane central register of controlled trials. Studies and abstracts investigating the relationship between vaccination and subsequent risk for the development of IBD were reviewed. Only randomized controlled trials, controlled clinical trials, cohort studies, and case-control studies investigating the risk for IBD after vaccination were eligible for inclusion. Childhood or adult immunizations with any vaccine type, at any dose, and with any vaccine schedule were used as inclusion criteria. Potentially eligible studies were identified via a literature search using the terms ulcerative colitis, Crohn's disease, inflammatory bowel disease, colitis, or ileitis. These were combined using the set operator AND with studies identified with the following terms: vaccine, vaccination, immunization, smallpox, poliomyelitis, tetanus, diphtheria, pertussis, mumps, rubella, measles, measles, mumps, rubella (MMR) vaccine, BCG, or influenza vaccine. Abstracts of the articles identified by the initial search were evaluated by the lead investigator for appropriateness to the study question, and all potentially relevant articles were obtained and evaluated in detail. We searched the bibliographies of all relevant articles obtained and any published reviews for additional studies. Abstract books of conference proceedings from major congresses in gastroenterology, Digestive Diseases Week, United European Gastroenterology Week, and the European Crohn's and Colitis Organisation between 2002 and 2013 were handsearched to identify potentially eligible studies published only in abstract form. Articles were assessed independently by 2 investigators using predesigned eligibility forms, according to the predefined eligibility criteria. Any disagreements between investigators were resolved by discussion.

\section{Outcome Assessment}

The outcome measures were defined a priori. The primary outcome assessed was the occurrence of IBD, $\mathrm{CD}$, or $\mathrm{UC}$ in patients receiving vaccination compared with patients without any vaccination. The metaanalysis evaluated different types of vaccines against tetanus, poliomyelitis, diphtheria, pertussis, smallpox, measles, mumps, rubella, and tuberculosis (BCG). Most of the studies analyzed the risk of developing IBD independently for each vaccine in the same patient population without reporting a global risk after vaccination. In these studies, each patient may have received 1 or more vaccine types. Because it was not possible to pool the risk of all vaccines for each study, we performed the meta-analysis for each vaccine type separately.

\section{Data Extraction}

All data were extracted by the lead investigator to a Microsoft Excel spreadsheet (XP professional edition; Microsoft Corp, Redmond, WA) as an odds ratio (OR) of developing IBD for each vaccine type in each study. If not available, the OR was calculated using the number of cases and controls exposed or not. In addition, the following clinical data were extracted for each study, when available: number of centers, country of origin, geographic region, type of study, inclusion period, inclusion criteria, methods for collecting past vaccination data, matching characteristics for case-control studies, 
disease type (UC or CD), total number of controls and IBD cases, and studied vaccines.

\section{Statistical Analysis}

Pooled results were expressed as the OR of IBD with vaccination compared with no vaccination, with $95 \%$ confidence intervals (CIs). Analyses were performed if at least 3 studies evaluating the same vaccination could be combined. If only 1 or 2 studies investigated the same vaccination, a description of studies was performed without a meta-analysis. Each meta-analysis was performed using only case-control studies, except for the measles vaccination, in which case-control and cohort studies were included in an analysis stratified by study design. For each meta-analysis, the method of Der Simonian and Laird $^{26}$ was used. According to this method, studies were considered as a random sample from a population of studies. Statistical heterogeneity was tested for each analysis. Because of heterogeneity among studies, a random-effect model was used to analyze data. All analyses were performed using R software and metafor package (R Development Core Team, 2011; R Foundation for Statistical Computing, Vienna, Austria). ${ }^{27}$

\section{Results}

\section{Literature Search}

The search strategy identified 428 citations, and 412 articles were excluded after reviewing the title and abstract (Supplementary Figure 1). Sixteen studies were retrieved for evaluation and 5 studies were excluded. Three studies were epidemiologic studies on IBD incidence during a vaccination campaign without estimation of the risk, 1 study was a case report, and 1 study did not have a control group. Finally, 11 studies were included in this systematic review and meta-analysis, ${ }^{11-21}$ and the characteristics of these studies are presented in Table 1. There were 8 case-control studies, ${ }^{11,14-18,20,21}$ of which 6 were populationbased $^{11,14,15,18,20,21}$ and 2 were hospital-based, ${ }^{16,17}$ and 3 were population-based cohort studies, ${ }^{12,13,19}$ including 3 cohorts reporting data on measles and on H1N1 influenza. Two studies investigated the occurrence of IBD in the pediatric population only. ${ }^{11,20}$ These studies reported on 11 vaccine types, against tuberculosis (BCG), diphtheria, tetanus, poliomyelitis, smallpox, pertussis, measles, rubella, mumps (including the MMR vaccine), and H1N1 influenza. All of these studies except 1 (H1N1 vaccine) investigated the effect of childhood vaccination. Because most of the studies analyzed the risk of developing IBD independently for each vaccine in the same patient population without reporting a global risk after vaccination, we performed the meta-analysis for each vaccine type separately (Table 2 ).

\section{Bacille Calmette-Guérin}

Three case-control studies (n1/4 963 patients) investigated the risk for IBD after BCG vaccination during childhood. ${ }^{11,18,21}$ The relative risk (RR) of developing IBD after BCG vaccination was 1.04 (95\% CI, 0.78-1.38). These figures were $1.17(95 \% \mathrm{CI}, 0.58-2.38 ; \mathrm{n} 1 / 43$ studies; 563 patients) and 0.98 (95\% CI, $0.73-1.30$; $\mathrm{n}$ 14 studies; 400 patients) for $\mathrm{CD}$ and $\mathrm{UC}$, respectively (Figure 1). There was heterogeneity only among studies on $\mathrm{CD}\left(\mathrm{I}^{2} 1 / 462 \% ; P^{1 / 4} \quad .07\right)$.

\section{Diphtheria- and Tetanus-Containing Vaccines}

Three case-control studies (n1/4 524 patients) investigated the risk of developing IBD after diphtheria or tetanus vaccination during childhood with 1 of these studies investigating only pediatric IBD. ${ }^{16,18,20}$ The RRs of developing IBD after vaccination with diphtheriacontaining vaccines and tetanus-containing vaccines were 1.24 (95\% CI, 0.80-1.94) and 1.27 (95\% CI, $0.77-2.08$ ), respectively (Figure 1). No heterogeneity was observed between the 3 studies.

\section{Poliomyelitis}

Three case-control studies (n1/4 666 patients) investigated the risk of developing IBD after a poliomyelitis vaccination during childhood ${ }^{11,18} ; 1$ study was published only as an abstract. ${ }^{20}$ The pooled RR of developing IBD after poliomyelitis vaccination was 1.79 (95\% CI, 0.88-3.66) (Figure 2A). The specific RRs of developing CD ( $\mathrm{n} 1 / 4345)$ and UC $\left(\mathrm{n}^{1} / 4174\right)$ were 2.28 (95\% CI, 1.12-4.63) and 3.48 (95\% CI, 1.24-9.71), respectively (Figure 2B). The exclusion of the study available only as an abstract and without details on risk for CD or UC did not change our results with a pooled RR of 2.61 (95\% CI, 1.46-4.68; $P 1 / 40012$; and $\mathrm{I}^{2} 0^{0} / 64 A^{2} P \quad 1 / 4$ .7817 , respectively). There was significant heterogeneity between the studies $\left(\mathrm{I}^{2} 1 / 467 \% ; P^{1 / 4} .049\right)$ (Figure 3).

\section{Pertussis}

Two case-control studies ( $\mathrm{n} / 4407$ patients) investigated the risk of developing IBD after a pertussis vaccination during childhood. ${ }^{16,18}$ The first study, which included 140 IBD patients born after 1968 in the United Kingdom and receiving a pertussis vaccination until 6 years of age, did not find a significant association between vaccination and the risk of developing IBD $(\mathrm{OR}, 1.00 ; 95 \%$ CI, 0.62-1.62). ${ }^{16}$ The second study from Denmark investigated childhood pertussis vaccinations in 267 patients diagnosed with IBD during 2003 to 2004 and matched controls. ${ }^{18}$ In this study, vaccination against pertussis increased the risk of developing IBD, especially UC (combined OR, 2.08; 95\% CI, 1.07-4.03). ${ }^{18}$ Because only 2 studies were available, we did not perform a meta-analysis. 
Table 1. Characteristics of Case-Control and Cohort Studies Included in the Meta-Analysis

\begin{tabular}{|c|c|c|c|c|c|c|c|c|c|}
\hline Study & Year & Country & Type & $\begin{array}{l}\text { Population } \\
\text { studied }\end{array}$ & Outcome & $\begin{array}{l}\text { Methods for } \\
\text { vaccine recall }\end{array}$ & Matching & Disease & Type of vaccine \\
\hline \multicolumn{10}{|l|}{ Case-control studies } \\
\hline Gilat et $\mathrm{al}^{17}$ & 1987 & $\begin{array}{l}\text { International } \\
\text { (United States, } \\
\text { United Kingdom, } \\
\text { Sweden, Holland, } \\
\text { Denmark, Israel, } \\
\text { France, Italy) }\end{array}$ & Hospital-based & $\begin{array}{l}\text { IBD patients } \\
\text { started } \\
<20 y,<25 y \\
\text { at the time } \\
\text { of the study, } \\
\text { at least } \\
6 \text { months } \\
\text { duration }\end{array}$ & Diagnosis of IBD & $\begin{array}{l}\text { Self-completion } \\
\text { questionnaire }\end{array}$ & $1: 2$, sex, age & $C D$ & $\begin{array}{l}\text { Smallpox, polio, } \\
\text { BCG, diphtheria, } \\
\text { measles, pertussis, } \\
\text { tetanus }\end{array}$ \\
\hline Feeney et $\mathrm{al}^{16}$ & 1997 & UK monocentric & Hospital-based & $\begin{array}{l}\text { Born in or after } \\
\quad 1968\end{array}$ & Diagnosis of IBD & $\begin{array}{l}\text { Data extraction } \\
\text { from database }\end{array}$ & $\begin{array}{l}1: 2 \text {, sex and year } \\
\text { of birth }\end{array}$ & IBD & $\begin{array}{r}\text { Pertussis, diphtheria, } \\
\text { tetanus, measles }\end{array}$ \\
\hline Davis et $\mathrm{al}^{15}$ & 2001 & US multicenter & Population-based & 1958-1989 & $\begin{array}{l}\text { IBD and cases } \\
\text { from age } 6 \text { mo } \\
\text { to index date } \\
\text { (diagnosis) or } \\
\text { reference date } \\
\text { for controls }\end{array}$ & $\begin{array}{l}\text { Data extraction } \\
\text { from database }\end{array}$ & $\begin{array}{c}1: 5, \text { sex, center } \\
\text { year of birth }\end{array}$ & IBD & Measles, MMR vaccine \\
\hline Baron et $\mathrm{al}^{11}$ & 2005 & France multicenter & Population-based & 1988-1997 & $\begin{array}{l}\text { IBD occurring } \\
\text { before age } 17 \mathrm{y}\end{array}$ & $\begin{array}{l}\text { Personal interview } \\
\text { by trained } \\
\text { investigators of } \\
\text { mother and child } \\
\text { (vaccine certificate } \\
\text { needed) }\end{array}$ & $\begin{array}{r}1: 1, \text { age, sex } \\
\text { living area }\end{array}$ & IBD & $\begin{array}{l}\text { MMR vaccine, } B C G, \\
\text { poliomyelitis, } \\
\text { smallpox }\end{array}$ \\
\hline Bernstein et $\mathrm{al}^{14}$ & 2006 & Canada monocentric & Population-based & NA & $\mathrm{IBD}<50 \mathrm{y}$ & $\begin{array}{l}\text { Questionnaire and } \\
\text { venipuncture }\end{array}$ & None & IBD & $\begin{array}{l}\text { Measles, mumps, } \\
\text { rubella }{ }^{a}\end{array}$ \\
\hline Hansen et $\mathrm{al}^{18}$ & 2011 & Denmark monocentric & Population-based & 2003-2004 & $\begin{array}{l}\text { Diagnosis of IBD } \\
\text { during inclusion } \\
\text { period }\end{array}$ & $\begin{array}{l}\text { Questionnaire-based } \\
\text { study }\end{array}$ & $\begin{array}{l}\text { Age, sex, } \\
\text { ethnicity, } \\
\text { geographic } \\
\text { location }\end{array}$ & IBD & $\begin{array}{l}\text { Pertussis, diphtheria, } \\
\text { tetanus, poliomyelitis, } \\
\text { BCG, measles, } \\
\text { rubella }\end{array}$ \\
\hline Shaw et $\mathrm{al}^{20}$ & 2012 & Canada multicenter & Population-based & $1988-$ & $\begin{array}{l}\text { IBD born after } 1989 \\
\text { and diagnosis } \\
\text { before } 2008\end{array}$ & $\begin{array}{l}\text { Data extraction, } \\
\text { vaccination } \\
\text { complete vs } \\
\text { incomplete or } \\
\text { none by age } 2 \text { y }\end{array}$ & $\begin{array}{l}\text { Age, sex, } \\
\text { living area } \\
\text { at time of } \\
\text { diagnosis }\end{array}$ & IBD & $\begin{array}{l}\text { Diphtheria, tetanus, } \\
\text { poliomyelitis, MMR } \\
\text { vaccine }\end{array}$ \\
\hline Villumsen et $\mathrm{al}^{21}$ & 2013 & Denmark (Copenhagen) & Population-based C & $\begin{array}{c}\text { Children born } \\
\text { between } \\
1965 \text { and } \\
1976\end{array}$ & $\begin{array}{l}\text { Incidental diagnosis } \\
\text { of IBD (1977- } \\
\text { 1994) }\end{array}$ & $\begin{array}{l}\text { Data extraction from } \\
\text { database }\end{array}$ & Age, sex & $C D$ & BCG, smallpox \\
\hline
\end{tabular}




\section{Smallpox}

Three case-control studies ( $11 / 41255$ patients) investigated the risk of developing IBD after a smallpox vaccination. ${ }^{17,21}$ The pooled RR of developing IBD after a smallpox vaccination was $1.08\left(95 \% \mathrm{CI}, 0.70-1.67 ; P_{4} .72\right)$, without heterogeneity between the studies (Figure 4).

\section{Measles, Rubella, and Mumps Vaccines}

Eight studies ( $\mathrm{n} 1 / 41366$ patients) investigated the risk of developing IBD after measles or MMR vaccination. ${ }^{11,12,14-16,18-20}$ Four studies investigated vaccination against measles with only live or attenuated vaccines, ${ }^{12,16,18,19} 2$ studies investigated only MMR vaccine, ${ }^{11,20}$ and 1 study investigated both vaccination strategies ${ }^{15}$ (Table 2). One other study focused on measles, rubella, and mumps serology, considering that most of the patients were seropositive because of childhood immunization (Table 2). ${ }^{14}$ Because 2 studies were population-based cohort studies ${ }^{12,19}$ a meta-analysis of measles-containing vaccines was stratified by study design.

The pooled RRs of developing IBD after measlescontaining vaccines in cohort and case-control studies were 1.33 (95\% CI, 0.31-5.80) and 0.85 (95\% CI, $0.60-1.20$ ), respectively (Figure 4). In the metaregression, results of cohort and case-control studies were not statistically different. The pooled RR of developing IBD after measles-containing vaccines (MMR included) by pooling cohort and case-control studies was 0.97 (95\% CI, 0.63-1.49; $P 1 / 4.89$ ) (Figure 4). There was significant heterogeneity between the studies $\left(\mathrm{I}^{2} \quad 1 / 4\right.$ $74 \% ; P<.001)$ (Figure 3 ); this heterogeneity was owing mostly to cohort studies with an $\mathrm{I}^{2}$ of $91 \%(P<.001)$ and $45 \%\left(\begin{array}{lll}P & 1 / 4 & .1023\end{array}\right)$ for cohort and case-control studies, respectively (Figure 4 ).

The RRs of developing IBD after a measles vaccination and MMR vaccination in case-control studies were 0.97 (95\% CI, 0.73-1.30; P .824) and 0.67 (95\% CI, $0.36-1.24 ; P^{1 / 4199)}$, respectively. No heterogeneity was observed between the studies. The RR of developing IBD after vaccination with rubella-containing vaccines (MMR included) was 0.65 (95\% CI, 0.33-1.25; A $\left._{4} .19\right)$. There was significant heterogeneity between the studies for rubella-containing vaccines ( $\left.\mathrm{I}^{2} 1 / 477 \% ; \quad P 1 / 4 \quad .002\right)$. Sensitivity analysis excluding the study using serology and not vaccination ${ }^{14}$ did not change the results (data not shown).

\section{H1N1 Vaccine}

Only 1 study investigated the risk of developing IBD after vaccination against the H1N1 influenza virus (Pandemrix, GlaxoSmithKline, London, UK) during the 2009 vaccination campaign in Sweden. ${ }^{13}$ It was a prospective population-based cohort study comparing the frequency of incident autoimmune diseases in patients 
Table 2. ORs of Developing IBD According to Vaccine Type in Case-Control and Cohort Studies

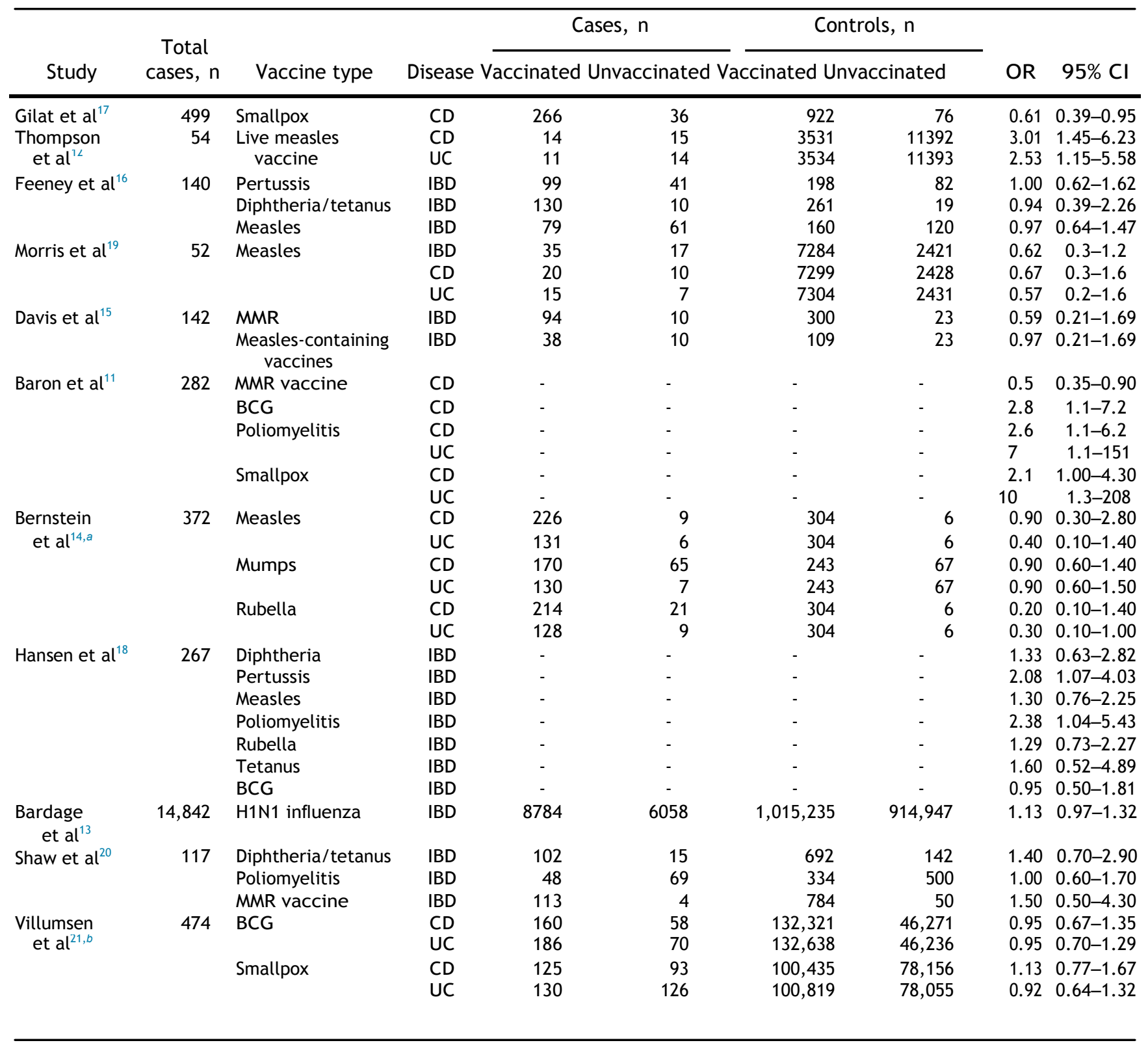

${ }^{a}$ Results are shown for measles, mumps, and rubella serology.

${ }^{b}$ Controls are expressed in person-years.

with or without vaccination. ${ }^{13}$ After adjusting the statistical model for age, sex, socioeconomic status, and health care consumption (number of hospital admissions and visits to specialist care 1 year before the pandemic period), the hazard ratio of developing IBD after the H1N1 vaccination was $1.13(95 \% \mathrm{CI}, 0.97-1.32){ }^{13}$

\section{Discussion}

Since the report by Thompson et al, ${ }^{12}$ the controversy about the risk of developing IBD after childhood immunization still is ongoing. This study reported that vaccination with the live measles vaccine was a risk for the development of consequent inflammatory disease, such as CD or UC. However, many publications after this report investigating vaccination with measles-containing vaccines did not show any association between immunization and IBD. Epidemiologic studies also investigated other vaccines such as BCG, diphtheria, tetanus, poliomyelitis, smallpox, pertussis, rubella, and mumps, reporting conflicting results. A positive association between BCG vaccination and CD were found in the study by Baron et al, ${ }^{11}$ with a high risk in patients with multiple immunization shots. This study also found a positive association between poliomyelitis and smallpox vaccination and $\mathrm{CD} .{ }^{11}$ One 2011 population-based, casecontrol study found a positive association be- tween pertussis and poliomyelitis vaccination and risk for IBD. ${ }^{18}$ On the contrary, 1 hospital-based, case-control 
Figure 1. Risk ratio of developing IBD after BCG, diphtheria, and tetanus vaccinations in casecontrol studies.

\section{Bacille Calmette-Guérin}

Baron 2005

Hansen 2011

Villumsen 2013

CD 12: $62 \%$ Peth: 0.0731

Hansen 2011

Villumsen 2013

UC 12: $0 \%$ Peth: 0.6078

Total I2: $28 \%$ Peth: 0.2336

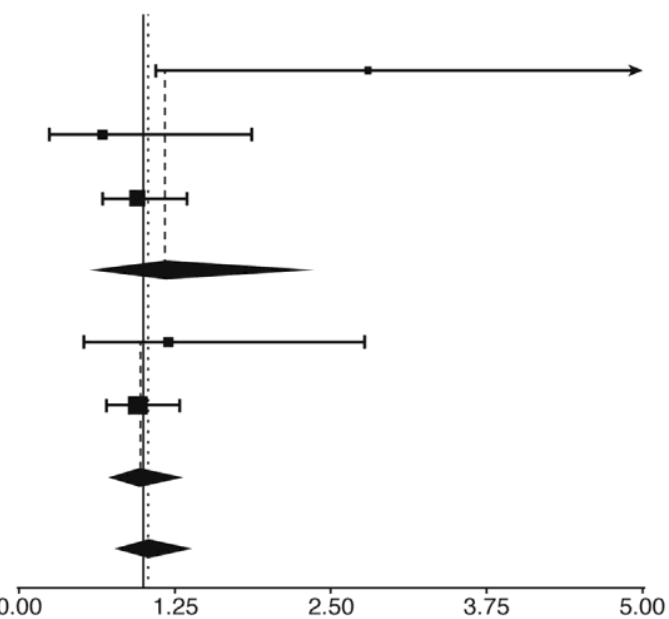

$2.80[1.09,7.16]$

$0.67[0.24,1.87]$

$0.95[0.67,1.35]$

$1.17[0.58,2.36]$

$1.20[0.52,2.77]$

$0.95[0.70,1.29]$

$0.98[0.73,1.30]$

$1.04[0.78,1.38]$

\section{Diptheria}

Feeney 1997

Hansen 2011

Shaw 2012

IBD I2: 0\% Peth: 0.7682

\section{Tetanus}

Feeney 1997

Hansen 2011

Shaw 2012

IBD I2: 0\% Peth: 0.7096

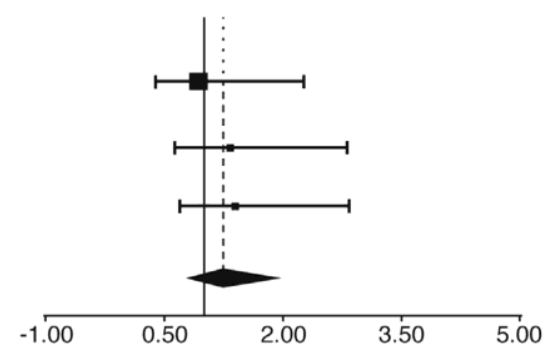

$0.94[0.39,2.26]$

$1.33[0.63,2.81]$

$1.40[0.69,2.85]$

$1.24[0.80,1.94]$

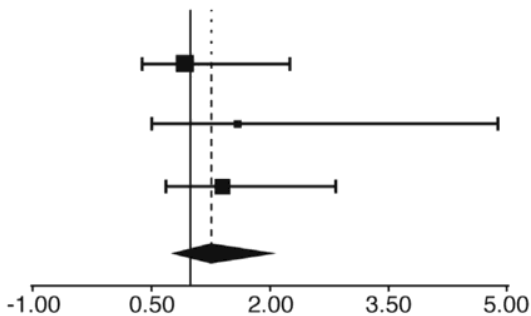

$0.94[0.39,2.26]$

$1.60[0.52,4.91]$

$1.40[0.69,2.85]$

$1.27[0.77,2.08]$

\section{Poliomyelitis}

A

Baron 2005

Hansen 2011

Shaw 2012

IBD I2: $67 \%$ Peth: 0.0494

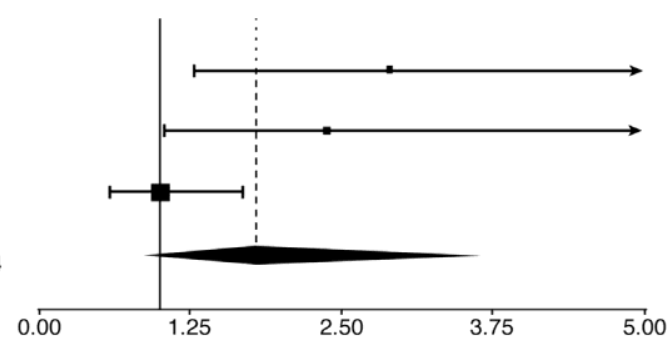

$2.90[1.28,6.55]$

$2.38[1.04,5.44]$

$1.00[0.59,1.68]$

$1.79[0.88,3.66]$

B

Baron 2005

Hansen 2011

CD 12: 0\% Peth: 0.606

Baron 2005

Hansen 2011

UC 12: $0 \%$ Peth: 0.5397

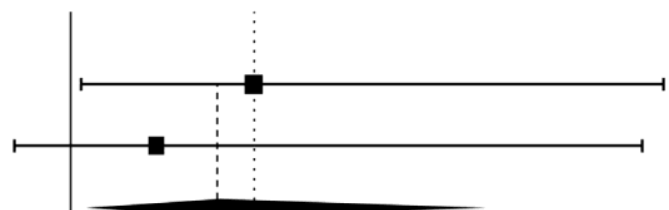

$1.75[0.51,5.99]$

$2.28[1.12,4.63]$

Figure 2. Risk ratio of developing IBD after poliomyelitis vaccination in case-control studies. (A) Meta-analysis using all studies reporting the risk for IBD. (B) Meta-analysis with studies reporting the

Total I2: 0\% Peth: 0.7817

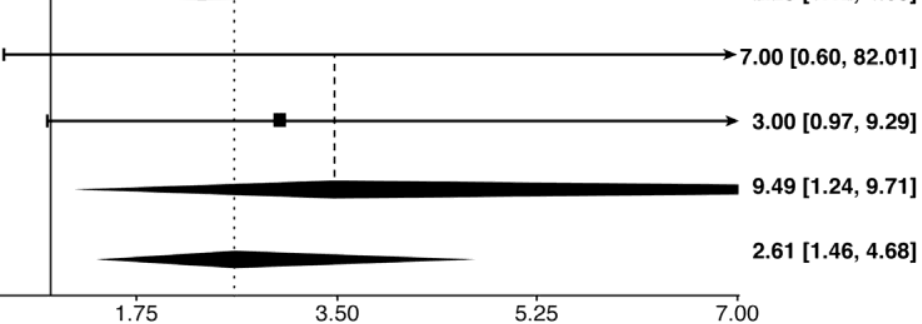
specific risk for Crohn's disease and ulcerative colitis. 


\section{Poliomyelitis vaccine}

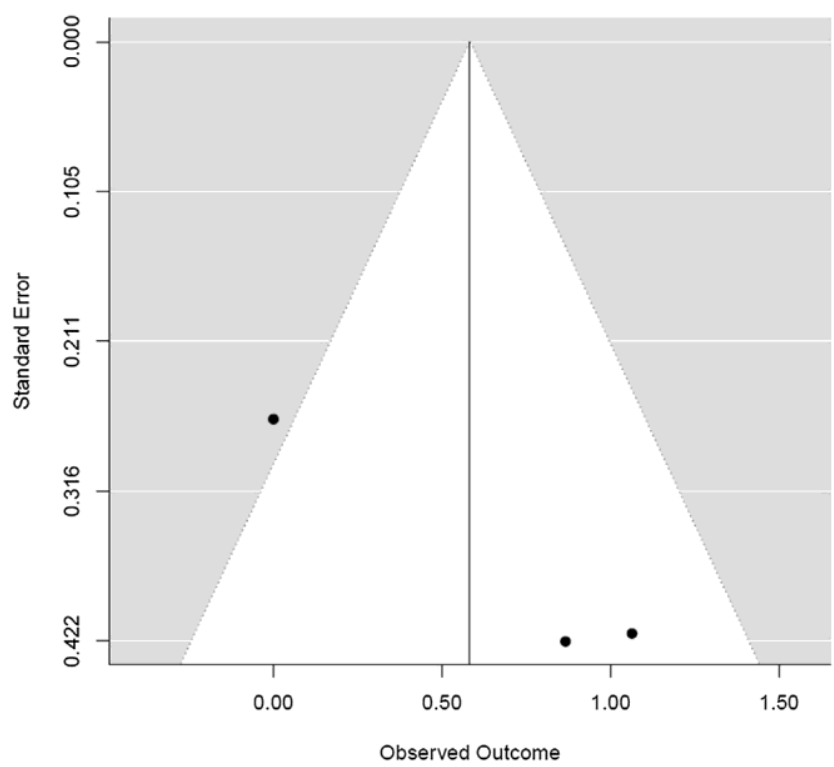

Measles containing vaccines

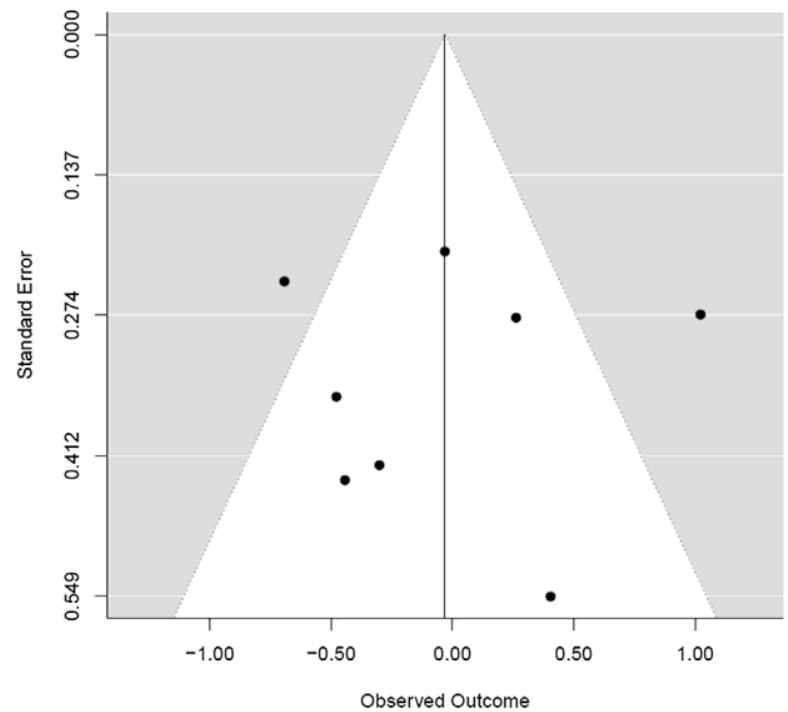

Figure 3. Funnel plots for poliomyelitis and measles vaccines.

study published in 1987 found a protective role of smallpox vaccination against $\mathrm{CD} .{ }^{17}$

Including 11 studies, 8 case-control studies, of which 6 were population-based and 2 were hospital-based, and 3 population-based cohort studies, we performed a metaanalysis of the risk of developing IBD after childhood or adult vaccination. Of note, the majority of the studies included focused only on childhood vaccination and 1 study investigated the H1N1 vaccine in adults. Overall, our results did not find any significant increased risk of developing IBD after childhood immunization with BCG, diphtheria, tetanus, poliomyelitis, smallpox, pertussis, measles, mumps, and rubella-containing vaccines. The study that investigated $\mathrm{H} 1 \mathrm{~N} 1$ vaccination in adults did not find any significantly increased risk of developing
IBD after this vaccination. Regarding poliomyelitis vaccination, 2 of the 3 studies analyzed in the metaanalysis reported a significant risk of developing IBD after vaccination. The other study was published only as an abstract and did not provide details for CD and UC. When we performed a sensitivity analysis without the study published as an abstract, we found a positive association between poliomyelitis vaccination and the risk of developing CD or UC (2.28 [95\% CI, 1.12-4.63] and 3.48 [95\% CI, 1.24-9.71], respectively). Regarding pertussis vaccination, only 2 studies reported a risk of developing IBD, with conflicting results. ${ }^{16,18}$

The results of this meta-analysis are globally reassuring regarding the risk of developing IBD after childhood vaccination. Vaccines that are developed to protect against an infectious disease or its consequences are, for the majority, not a risk for the subsequent development of intestinal inflammatory disease. The strength of our study was the large number of patients included in the meta-analysis, with 2399 IBD patients and 33,747 controls in 10 studies investigating 10 vaccine types (BCG, diphtheria, tetanus, poliomyelitis, smallpox, pertussis, measles, rubella, mumps, and the MMR vaccine), although not all vaccines were investigated in each IBD patient. The study investigating the H1N1 vaccine included 14,842 patients with IBD. Limitations of our work mainly were owing to the fact that studies investigating the risk of developing IBD after vaccination were extremely heterogeneous regarding their study design, sample size, geographic location, and vaccination recall methods. Indeed, we found significant heterogeneity between the studies for poliomyelitis- and measlescontaining vaccines. Vaccination protocols varied between countries and evolved through the years, with different types of vaccines and schedules leading to difficulties in risk evaluation. Moreover, some vaccines used were live attenuated vaccines such as measles, oral poliomyelitis, or whole-cell pertussis vaccines, and may have a different effect on immune system activation and dysregulation compared with other inactivated acellular vaccines. In addition, the method of recalling the vaccination status in each patient represented a limitation in these studies. Indeed, half of the studies used a database to collect the vaccination status of patient, but the other half used only a self-completed questionnaire or an interview, which may have lead to recall bias. Specific bias present only in certain studies could have led to heterogeneity as well as publication bias because statistically significant results come mostly from smaller studies, ${ }^{11,12,18}$ as illustrated by the Funnel plot profile for poliomyelitis. However, the small number of studies for most vaccines did not allow us to explore further publication bias and heterogeneity. Of note, the study by Gilat et $\mathrm{al},{ }^{17}$ which collected data about several vaccinations, only reported detailed positive results for smallpox vaccination, indicating that no association was found for the other vaccines without providing any detail. A major limitation of the study was that all the 

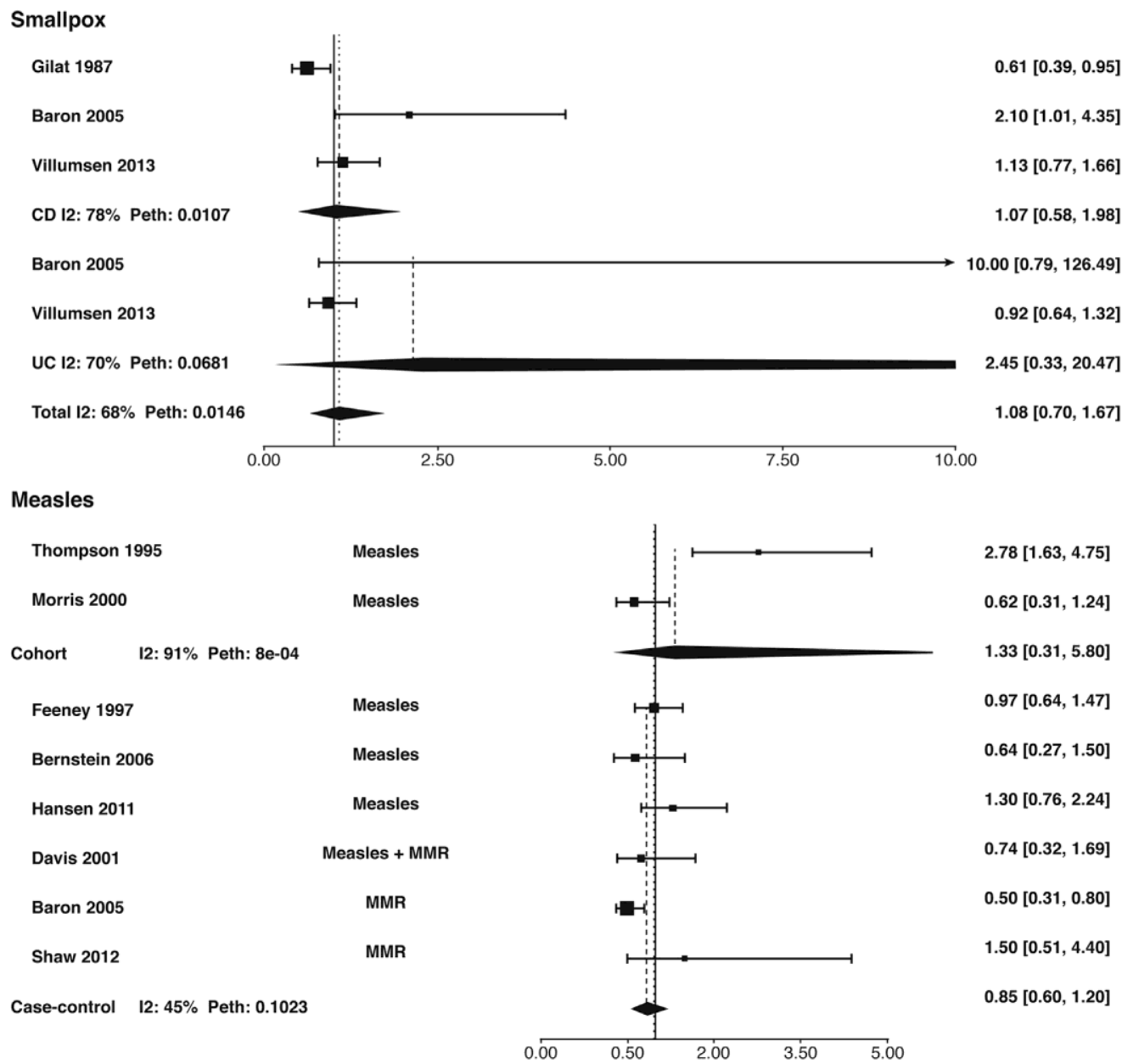

$2.78[1.63,4.75]$
$0.62[0.31,1.24]$
$1.33[0.31,5.80]$
$0.97[0.64,1.47]$
$0.64[0.27,1.50]$
$1.30[0.76,2.24]$
$0.74[0.32,1.69]$
$0.50[0.31,0.80]$
$1.50[0.51,4.40]$
$0.85[0.60,1.20]$
Figure 4. Risk ratio of developing IBD after smallpox and measles vaccinations in casecontrol and cohort studies.
Measles

case-control studies included in the meta-analysis evaluated more than 1 vaccine at a time and that it was not possible to determine specifically the risk related to only 1 vaccine. Individuals with multiple vaccinations may be at higher risk for IBD, as suggested in the study by Baron et al. ${ }^{11}$

In this meta-analysis, although the overall analysis of all studies investigating the poliomyelitis vaccination did not find any increased risk of developing IBD, sensitivity analysis indicated that patients receiving the poliomyelitis vaccine may be at risk for developing CD or UC. Indeed, 2 studies showed an increased risk of developing IBD after childhood vaccination with the poliomyelitis vaccine $^{11,18}$ and only 1 study published as an abstract did not find a significantly increased risk. ${ }^{20}$ The poliomyelitis vaccine is used widely in developed countries and mostly combined with diphtheria- or tetanuscontaining vaccines. ${ }^{28,29}$ These 3 national studies investigating the poliomyelitis vaccination did not provide any detail on the route of administration of the vaccine, which may be a critical factor to explain differences in results. ${ }^{11,18,20}$ Indeed, 2 types of poliomyelitis vaccine, an oral live vaccine (OPV) and an injected inactivated vaccine (IPV) have been used during the past decades worldwide to eradicate poliomyelitis. ${ }^{28} \mathrm{We}$ may hypothesize that live attenuated OPV may have a greater impact on activating the mucosal immune system than the IPV, and have different effects on the risk of IBD. Although publications did not contain any information about the route of administration, extrapolation could be made by looking at public vaccination history in involved countries. ${ }^{28,30,31}$ In the French study by Baron et $\mathrm{al}^{11}$ patients were recruited beginning in 1988 and should have received the IPV because France had withdrawn the utilization of the OPV since 1983. In Denmark, combined vaccination with OPV and IPV has been practiced since 1966 and has been replaced only recently with IPV vaccination alone. ${ }^{30}$ Patients in the Danish study by Hansen et $\mathrm{al}^{18}$ all would have been vaccinated with the IPV. In Manitoba, Canada, after having adopted a mixed schedule of IPV and OPV since 1962, switched to an exclusive OPV schedule during the 1970s. Then, between 1994 and 1997 Manitoba transitioned to the exclusive use of the IPV. ${ }^{28}$ Therefore, we may hypothesize that the majority of patients in the Canadian study from Shaw et $\mathrm{al}^{20}$ (pediatric IBD cases in Manitoba born after 1989 and diagnosed before 2008) may have received only the OPV. This difference in vaccine type if true may explain the contradictory results of these studies. Heterogeneity in the meta-analysis results also could be explained by differences in study design (2 studies investigated only pediatric IBD patients ${ }^{11,20}$ ) or in the samples (the study 
by Shaw et $\mathrm{al}^{20}$ had half as many IBD cases as the 2 other studies $^{11,18}$ ). Moreover, methods for vaccination recall were different between these studies, with positive studies using questionnaires and the negative study using a population-based database of immunizations administered in Manitoba. In addition, the IPV contains many adjuvants that may be involved in stimulation of the immune system. ${ }^{24}$ Indeed, vaccine adjuvants such as thimerosal and aluminum, the 2 major salt-based adjuvants that have been used or still are used in vaccines, may participate in the development of inflammatory disorders. ${ }^{10,32}$ Thimerosal, an ethyl mercury-containing compound that has been used as a preservative in multidose vials of vaccines to prevent bacterial and fungal contamination of those vials, now has been removed completely from vaccines whereas aluminum salts used to boost the immune response still are present in most of the vaccines used in children. Both thimerosal and aluminum have been suspected to be involved in various inflammatory or neurologic disorders. ${ }^{10,32}$ Thus, the lack of data about the exact composition of vaccines used in these studies has lead to difficulty in interpreting results.

We also found conflicting results on pertussis vaccination and the risk of developing IBD in 2 studies. ${ }^{16,18}$ There was no information about the type of pertussis vaccine, but during the study period in the United Kingdom and Denmark a whole-cell pertussis vaccine was used exclusively. ${ }^{33,34}$ Other differences in the design of these studies may explain the conflicting results because the UK study was hospital-based whereas the Danish study was population-based. Moreover, in the study by Hansen et al, ${ }^{18}$ poliomyelitis virus found to be associated with an increased risk of IBD may act as a confounding factor. Interestingly, the UK study by Feeney et $\mathrm{al}^{16}$ did not report on poliomyelitis vaccination and during the study period only the OPV was used in the United Kingdom.

In conclusion, results of this meta-analysis do not support a role of childhood immunization or H1N1 vaccination in the development of IBD. The association between the poliomyelitis vaccine and risk for $\mathrm{CD}$ or UC should be analyzed cautiously because of study heterogeneity and will require further investigation.

\section{Supplementary Material}

Note: To access the supplementary material accompanying this article, visit the online version of Clinical Gastroenterology and Hepatology at www.cghjournal.org, and at http://dx.doi.org/10.1016/j.cgh.2015.04.179.

\section{References}

1. Baumgart DC, Carding SR. Inflammatory bowel disease: cause and immunobiology. Lancet 2007;369:1627-1640.

2. Xavier RJ, Podolsky DK. Unravelling the pathogenesis of inflammatory bowel disease. Nature 2007;448:427-434.
Jostins L, Ripke S, Weersma RK, et al. Host-microbe interactions have shaped the genetic architecture of inflammatory bowel disease. Nature 2012;491:119-124.

4. Cortot A, Pineton de Chambrun G, Vernier-Massouille G, et al. [Inflammatory bowel disease: genetic or environmental diseases?]. Gastroenterol Clin Biol 2009;33:681-691.

5. Kaplan G. Air pollution and the inflammatory bowel diseases. Inflamm Bowel Dis 2011;17:1146-1148.

6. Kaser A, Zeissig S, Blumberg RS. Genes and environment: how will our concepts on the pathophysiology of IBD develop in the future? Dig Dis 2010;28:395-405.

7. Halfvarson J, Bodin L, Tysk C, et al. Inflammatory bowel disease in a Swedish twin cohort: a long-term follow-up of concordance and clinical characteristics. Gastroenterology 2003;124:1767-1773.

8. Loftus EV Jr. Clinical epidemiology of inflammatory bowel disease: incidence, prevalence, and environmental influences. Gastroenterology 2004;126:1504-1517.

9. Molodecky NA, Kaplan GG. Environmental risk factors for inflammatory bowel disease. Gastroenterol Hepatol (N Y) 2010; 6:339-346.

10. Pineton de Chambrun G, Body-Malapel M, Frey-Wagner I, et al. Aluminum enhances inflammation and decreases mucosal healing in experimental colitis in mice. Mucosal Immunol 2014; 7:589-601.

11. Baron S, Turck D, Leplat C, et al. Environmental risk factors in paediatric inflammatory bowel diseases: a population based case control study. Gut 2005;54:357-363.

12. Thompson NP, Montgomery SM, Pounder RE, et al. Is measles vaccination a risk factor for inflammatory bowel disease? Lancet 1995;345:1071-1074.

13. Bardage C, Persson I, Ortqvist A, et al. Neurological and autoimmune disorders after vaccination against pandemic influenza A (H1N1) with a monovalent adjuvanted vaccine: population based cohort study in Stockholm, Sweden. BMJ 2011; 343:d5956.

14. Bernstein CN, Rawsthorne P, Blanchard JF. Population-based case-control study of measles, mumps, and rubella and inflammatory bowel disease. Inflamm Bowel Dis 2007;13:759-762.

15. Davis RL, Kramarz P, Bohlke K, et al. Measles-mumps-rubella and other measles-containing vaccines do not increase the risk for inflammatory bowel disease: a case-control study from the Vaccine Safety Datalink project. Arch Pediatr Adolesc Med 2001;155:354-359.

16. Feeney $\mathrm{M}$, Ciegg $\mathrm{A}$, Winwood $\mathrm{P}$, et al. A case-control study of measles vaccination and inflammatory bowel disease. The East Dorset Gastroenterology Group. Lancet 1997;350:764-766.

17. Gilat $T$, Hacohen $D$, Lilos $P$, et al. Childhood factors in ulcerative colitis and Crohn's disease. An international cooperative study. Scand J Gastroenterol 1987;22:1009-1024.

18. Hansen TS, Jess T, Vind I, et al. Environmental factors in inflammatory bowel disease: a case-control study based on a Danish inception cohort. J Crohns Colitis 2011;5:577-584.

19. Morris DL, Montgomery SM, Thompson NP, et al. Measles vaccination and inflammatory bowel disease: a national British Cohort Study. Am J Gastroenterol 2000;95:3507-3512.

20. Shaw SY, Blanchard JF, Bernstein CN. Early childhood immunizations are not associated with pediatric IBD: a population-based analysis. Gastroenterology 2012;142(Suppl 1):S-88.

21. Villumsen $M$, Jess $T$, Sorup $S$, et al. Risk of inflammatory bowel disease following bacille Calmette-Guerin and smallpox 
vaccination: a population-based Danish case-cohort study. Inflamm Bowel Dis 2013;19:1717-1724.

22. Bach JF. The effect of infections on susceptibility to autoimmune and allergic diseases. N Engl J Med 2002;347:911-920.

23. Schattner A. Consequence or coincidence? The occurrence, pathogenesis and significance of autoimmune manifestations after viral vaccines. Vaccine 2005;23:3876-3886.

24. Lerner A. Aluminum is a potential environmental factor for Crohn's disease induction: extended hypothesis. Ann N Y Acad Sci 2007;1107:329-345.

25. Kanwal F, White D. Systematic reviews and meta-analyses. Clin Gastroenterol Hepatol 2012;10:1184-1186.

26. DerSimonian R, Laird N. Meta-analysis in clinical trials. Control Clin Trials 1986;7:177-188.

27. Viechtbauer W. Conducting meta-analyses in $\mathrm{R}$ with the metafor package. J Stat Softw 2010;36:1-48.

28. Barreto L, Van Exan R, Rutty CJ. Polio vaccine development in Canada: contributions to global polio eradication. Biologicals 2006;34:91-101.

29. Griffiths $E$, Wood D, Barreto L. Polio vaccine: the first 50 years and beyond. Biologicals 2006;34:73-74.

30. Bottiger $M$. The elimination of polio in the Scandinavian countries. Public Health Rev 1993;21:27-33.
Malvy DJ, Drucker J. Elimination of poliomyelitis in France: epidemiology and vaccine status. Public Health Rev 1993; 21:41-49.

32. Geier DA, King PG, Hooker BS, et al. Thimerosal: clinical, epidemiologic and biochemical studies. Clin Chim Acta 2015; 444:212-220.

33. Amirthalingam G, Gupta S, Campbell H. Pertussis immunisation and control in England and Wales, 1957 to 2012: a historical review. Euro Surveill 2013;18:38.

34. Hviid A, Stellfeld $M$, Andersen PH, et al. Impact of routine vaccination with a pertussis toxoid vaccine in Denmark. Vaccine 2004;22:3530-3534.

Reprint requests

Address requests for reprints to: Guillaume Pineton de Chambrun, MD, PhD, Gastroenterology and Hepatology Department, Montpellier University Hospital, 80 Avenue Augustin Fliche, F-34000, Montpellier, France. e-mail: gpinetondechambrun@yahoo.fr; fax: (33) 4-67-33-75-75.

Acknowledgments

The authors thank the Digestscience Foundation for its non-financial support.

Conflicts of interest

The authors disclose no conflicts.

31. 


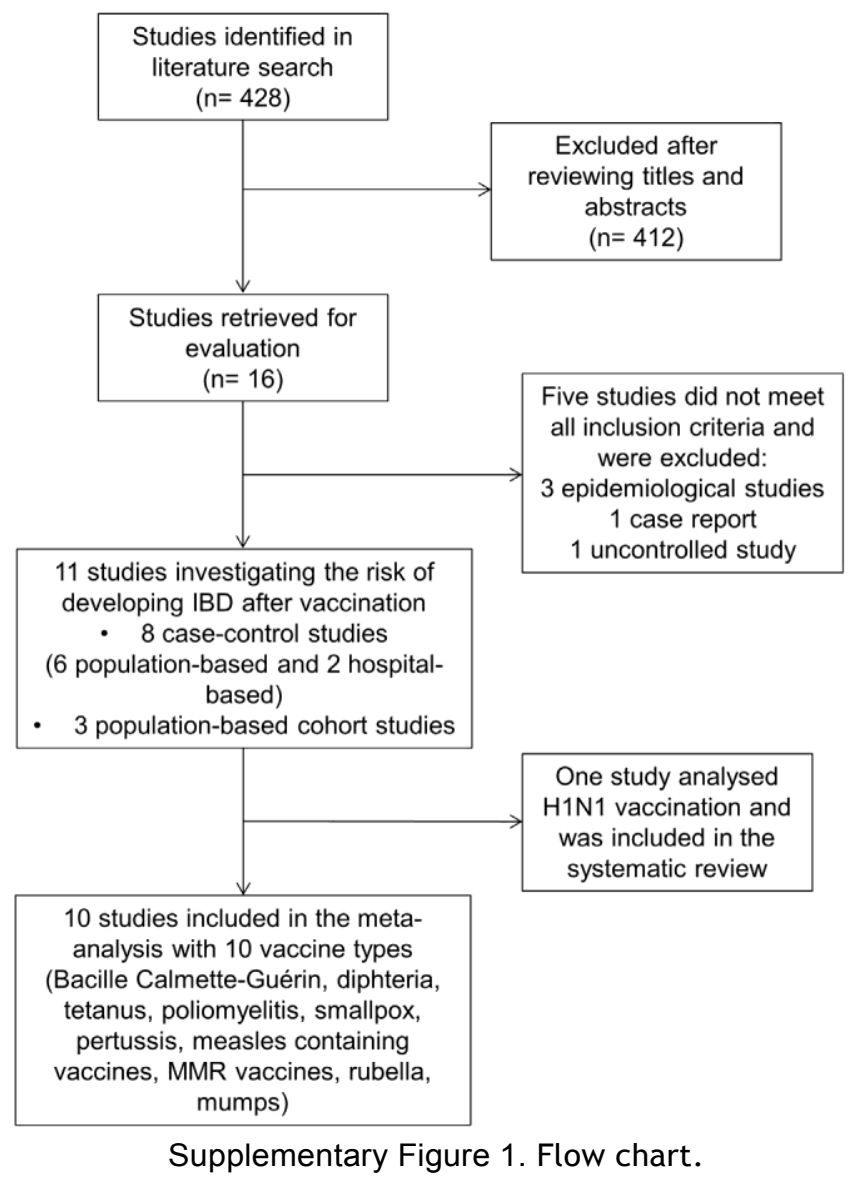

